\title{
Fits, pyridoxine, and hyperprolinaemia type II
}

\author{
Valerie Walker, Graham A Mills, Sheila A Peters, W Louis Merton
}

Department of

Chemical Pathology,

Southampton General

Hospital, Tremona

Road, Southampton

SO16 6YD, UK

V Walker

School of Pharmacy and Biological

Sciences, University of

Portsmouth, White

Swan Road,

Portsmouth PO1 2DT,

UK

G A Mills

Department of

Paediatrics, St Mary's

Hospital, Milton Road,

Portsmouth PO3 6AD,

UK

S A Peters

Department of

Neurophysiology, St

Mary's Hospital

W L Merton

Correspondence to:

Dr Walker

Accepted 22 November 1999

\begin{abstract}
The rare inherited disorder hyperprolinaemia type II presents with fits in childhood, usually precipitated by infection. A diagnosis of hyperprolinaemia type II and vitamin $B_{6}$ deficiency was made in a well nourished child with fits. It is thought that pyridoxine deficiency was implicated in her fits and was the result of inactivation of the vitamin by the proline metabolite, pyrroline-5-carboxylate. (Arch Dis Child 2000;82:236-237)
\end{abstract}

Keywords: pyridoxine; fits; hyperprolinaemia type II; pyrroline-5-carboxylate

Hyperprolinaemia type II (McKusick 23591) is a rare autosomal recessive disorder caused by deficiency of $\Delta^{1}$-pyrroline-5-carboxylate dehydrogenase. The biochemical abnormalities are a 10-15-fold increase in plasma proline, accumulation of pyrroline-5-carboxylate, and increased urinary proline, hydroxyproline, and glycine. ${ }^{1}$ Clinical presentation is with convulsions in childhood, usually precipitated by infection. In one reported case these were associated with an erythematous rash. Most affected adults and some children detected by family screening do not have fits and there is probably no association with learning difficulties or developmental delay. ${ }^{2}$

The child reported was found to have both hyperprolinaemia type II and vitamin $\mathrm{B}_{6}$

Table 1 Diagnostic biochemical investigations

\begin{tabular}{|c|c|c|}
\hline & Value & Reference range \\
\hline \multicolumn{3}{|l|}{ Hyperprolinaemia type II } \\
\hline \multicolumn{3}{|l|}{ Plasma $(\mu \mathrm{mol} / \mathrm{l})(\mathrm{n}=5)$} \\
\hline Proline & $2290-2900$ & $89-281$ \\
\hline Hydroxyproline & $6-90$ & $<10$ \\
\hline Ornithine & $131-145$ & $27-103$ \\
\hline \multicolumn{3}{|c|}{ Urine $(\mu \mathrm{mol} / \mathrm{mmol}$ creatinine $)(\mathrm{n}=5)$} \\
\hline Proline & $3700-47500$ & $<13$ \\
\hline Hydroxyproline & $85-420$ & $<13$ \\
\hline Glycine & $1432-4055$ & $<356$ \\
\hline Ornithine & $18-33$ & $<8$ \\
\hline $\mathrm{N}$-(pyrrole-2-carboxyl)-glycine & Present & Not detected \\
\hline \multicolumn{3}{|l|}{ Vitamin $B_{6}$ deficiency } \\
\hline \multicolumn{3}{|l|}{ Plasma $(\mathrm{nmol} / \mathrm{l})(\mathrm{n}=2)$} \\
\hline Pyridoxal phosphate & $23.5 ; 22.7$ & $24.3-81.0$ \\
\hline Pyridoxic acid & $1.0 ; 2.7$ & $10.9-27.3$ \\
\hline \multicolumn{3}{|c|}{ Urine $(\mu \mathrm{mol} / \mathrm{mmol}$ creatinine $)(\mathrm{n}=1)$} \\
\hline \multirow[t]{3}{*}{ Pyridoxic acid } & 0.4 & $0.5-2.3$ \\
\hline & \multicolumn{2}{|c|}{ Urine ( $\mu$ mol/mmol creatinine) } \\
\hline & Basal (reference) & Peak \\
\hline \multicolumn{3}{|l|}{ Tryptophan load test } \\
\hline Xanthurenic acid & $12.4(0.3-1.5)$ & $3165.9^{\star}$ \\
\hline Kynurenic acid & $2.5(0.8-3.0)$ & $524.9^{\star}$ \\
\hline Kynurenine & $3.1(1.1-3.7)$ & $545.5^{\star}$ \\
\hline 2-Aminoacetophenone & Not detected & Present $†$ \\
\hline
\end{tabular}

Plasma vitamin $\mathrm{B}_{6}$ was measured by high performance liquid chromatography (Dunn Nutrition Centre, Cambridge; department of clinical biochemistry, Glasgow Royal Infirmary). Tryptophan metabolites and pyridoxic acid were measured in urease treated extracted urine by gas chromatography mass spectrometry with single ion monitoring. Basal values are compared with in house paediatric reference ranges.

${ }^{\star}$ Reference is less than 10 -fold increase above basal; $\uparrow$ Not reported deficiency from amino acid and organic acid abnormalities when she presented with fits and encephalopathy. We speculate that pyridoxine deficiency was implicated in her fits and that it was caused by inactivation of the vitamin by the proline metabolite pyrroline-5-carboxylate. This would be a unique cause of increased vitamin dependency. It would account for the fits in hyperprolinaemia type II, which are currently unexplained.

\section{Case report}

A previously well girl had a febrile convulsion at 18 months. She recovered completely. At 20 months she became sleepy, lethargic, and fed poorly in association with pneumonia. She had three convulsions within 15 hours, two lasting more than five minutes and one 20 minutes. After these, she was encephalopathic with back arching and purposeless movements, areflexic, but breathing normally. An electroencephalogram (EEG) six hours after her fits did not show any discharges; slow activity was quite prominent with spindles appropriate for sleep. On brief arousal, low activities were seen with no excess of slow activity to indicate an overt encephalopathy. However, 24 hours later, when she was awake and not fitting, the EEG was very abnormal (fig 1). Large irregular slow activities $(2-3 \mathrm{~Hz}, 200 \mu \mathrm{V})$ mixed with rather repetitive sharp/polysharp waves and occasional spikes were seen over both hemispheres with variable localisation. Computerised brain tomography was normal. She recovered slowly over five days. The EEG became normal. Three months later she had a severe nappy rash for three to four weeks, which was resistant to local treatment. There have been no more fits (see addendum). After demonstrating pyridoxine deficiency, she was treated with $50 \mathrm{mg}$ pyridoxine orally daily from 32 months of age for five weeks, reducing to $10 \mathrm{mg}$ daily long term. At 3 years of age, she is growing along the 50th centile for height, 25th centile for weight, and is neurologically normal except for slight speech delay. She has a good, mixed diet and there have never been feeding or intestinal problems.

\section{Biochemical investigations}

Hyperprolinaemia type II was diagnosed from persisting amino acid and organic acid abnormalities (table 1). DNA analysis has excluded the mutation present in a large Irish kindred. ${ }^{3}$ Further DNA studies are planned. A skin biopsy for fibroblast enzyme confirmation is not justifiable at present. Novel findings in the acute urine sample were two metabolites of tryptophan: xanthurenic acid and a volatile degradation product of kynurenine, 2-aminoacetophenone. These abnormalities suggested vitamin $\mathrm{B}_{6}$ deficiency. ${ }^{4}$ Plasma 
A

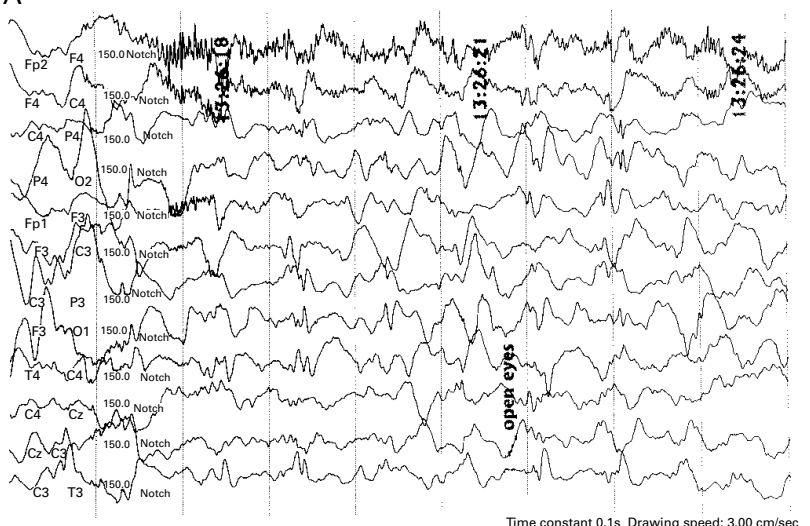

B

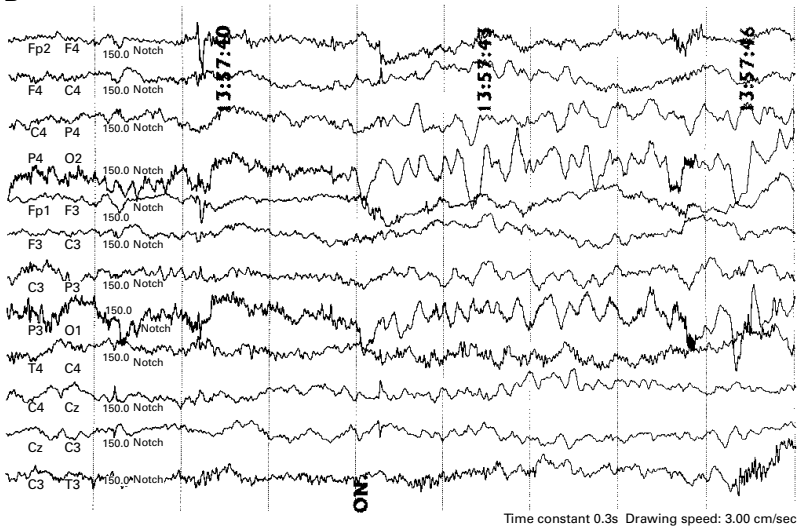

Figure 1 (A) The second electroencephalogram (EEG) 30 hours after admission, which was taken while the patient was awake and not fitting, shows runs of rather repetitive sharp/polysharp discharges mixed with excess slow activity (A). (B) Normal EEG on recovery. "On" marks passive eye closure with appearance of posterior rhythmic activity appropriate for age.

analysed by two laboratories when the child was well at 22 months and 28 months showed marginally low pyridoxal phosphate and greatly reduced pyridoxic acid, to concentrations that were barely detectable. Pyridoxic acid is the end product of vitamin $\mathrm{B}_{6}$ catabolism and low values indicate a deficiency. An oral L-tryptophan loading test $(100 \mathrm{mg} / \mathrm{kg}$ body weight) was carried out at 28 months of age to stress vitamin $\mathrm{B}_{6}$ metabolism. Random urine samples were collected for 7.5 hours after loading. Basal excretion of xanthurenic acid was increased and the response to loading was excessive, ${ }^{5}$ confirming vitamin $\mathrm{B}_{6}$ deficiency. In a follow up test after five weeks of $50 \mathrm{mg}$ pyridoxine orally daily, basal urine xanthurenic acid was normal $(1.1 \mu \mathrm{mol} / \mathrm{mmol}$ creatinine $)$, as was the post load excretion $(9.8 \mu \mathrm{mol} / \mathrm{mmol}$ creatinine). Co-incubation of pyridoxal, pyridoxal phosphate, and pyridoxamine with pyrroline-5-carboxylate at physiological $\mathrm{pH}$ in vitro produced new compounds demonstrable with gas chromatography mass spectrometry and nuclear magnetic resonance spectroscopy. Studies to characterise these are in progress (see addendum).

\section{Discussion}

Because vitamin $B_{6}$ occurs widely in food, symptomatic deficiency is rare. Nutritional deficiency in infants aged 6 weeks to 6 months fed autoclaved cows' milk caused irritability and generalised convulsions with EEG abnormalities. Adults treated with vitamin $\mathrm{B}_{6}$ antagonists and low pyridoxine diets also had epileptiform convulsions and sometimes a red scaly rash involving the eyes, nose, and perineum. ${ }^{4}$ Vitamin $B_{6}$ deficiency would explain the fits in our child and might have contributed to the severe nappy rash. The unusual EEG abnormalities in her acute illness resemble those in pyridoxine dependent epilepsy. ${ }^{6}$

Nutritional deficiency was not the explanation here. Alternatives are antagonism or inactivation of one of the physiological forms of vitamin $B_{6}$ (pyridoxal, pyridoxine, or pyridoxamine, or their phosphates). Antagonists are generally structural analogues of the $\mathrm{B}_{6}$ vitamins or agents that complex with them. ${ }^{7}$ Pyrroline-5carboxylate is a reactive compound that accumulates in hyperprolinaemia type II. We propose that it links covalently with one of the $B_{6}$ vitamins and inactivates it. Pyridoxal or pyridoxal phosphate are likely candidates because they have a very reactive aldehyde group. Our preliminary studies in vitro indicate that such an interaction is possible. We know of no other instance of an endogenous metabolite causing similar vitamin dependency.

We intend to treat our patient with pyridoxine $(10 \mathrm{mg} /$ day $)$ until she is 10 years old when the risk of fits should have decreased. ${ }^{2}$ Other children with the defect might also benefit from supplements and their plasma pyridoxal phosphate and pyridoxic acid should be measured.

We thank Professor D Valle, The Johns Hopkins University School of Medicine, Baltimore, USA for undertaking DNA mutation analysis.

\section{Addendum}

The child was admitted in December 1999 (aged 4 years 7 months) with a lower respiratory tract infection. She had fits, was unrousable, and encephalopathic as before. She had not been receiving vitamin $B_{6}$ at home. She was given $110 \mathrm{mg}$ been receiving vitamin $\mathrm{B}_{6}$ at home. She was given $110 \mathrm{mg}$
pyridoxine intravenously in divided doses. She was responsive pyridoxine intravenously in divided doses. She was respons

We have now characterised the conjugate of pyridoxal phosphate and pyrroline-5-carboxylate, and are preparing a further [analytical] publication.

1 Phang JM, Yeh GC, Scriver CR. Disorders of proline and hydroxyproline metabolism. In: Scriver CR, Beaudet AL, Sly WS, Valle D, eds. The metabolic and molecular bases of inherited disease, 7th ed. New York: McGraw-Hill, 1995:1125-46.

2 Flynn MP, Martin MC, Moore PT, et al. Type II hyperprolinaemia in a pedigree of Irish travellers (nomads). Arch Dis Child 1989;64:1699-707.

3 Geraghty MT, Vaughn D, Nicholson AJ, et al. Mutations in the $\Delta^{1}$-pyrroline-5-carboxylate dehydrogenase gene cause type II hyperprolinemia. Hum Mol Genet 1998;7:1411-15.

4 György P. Vitamin $B_{6}$ deficiency effects in man. In: Sebrell $\mathrm{WH}$, Harris RS, eds. The vitamins, 2 nd ed, Vol. 2. New York: Academic Press, 1968:90-104.

5 Komrower GM, Westall R. Hydroxykynureninuria. Am $\mathcal{F}$ Dis Child 1967;113:77-80.

6 Mikati MA, Trevathan E, Krishnamoorthy KS, Lombroso CT. Pyridoxine-dependent epilepsy: EEG investigations and long-term follow-up. Electroencephalogr Clin Neurophysiol 1991;78:215-21.

7 Klosterman HJ. Vitamin $B_{6}$ antagonists and antimetabolites. In: Dolphin D, Poulson R, Avramovic O, eds. Coenzymes and cofactors volume I. Vitamin $B_{6}$. Pyridoxal phosphate. New York: John Wiley, 1986:392-415. 